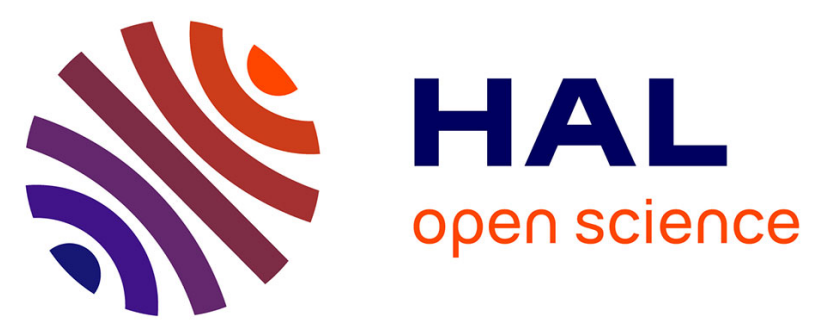

\title{
Design of near-infrared dyes for nonlinear optics: toward optical limiting applications at telecommunication wavelengths
}

Quentin Bellier, Pierre-Antoine Bouit, Kenji Kamada, Patrick Feneyrou, E. Malmström, Olivier Maury, Chantal Andraud

\section{To cite this version:}

Quentin Bellier, Pierre-Antoine Bouit, Kenji Kamada, Patrick Feneyrou, E. Malmström, et al.. Design of near-infrared dyes for nonlinear optics: toward optical limiting applications at telecommunication wavelengths. SPIE Europe Security + Defence, 2009, Berlin, Germany. pp.74870G, 10.1117/12.831226 . hal-02412434

\section{HAL Id: hal-02412434 \\ https://hal.science/hal-02412434}

Submitted on 16 Jul 2020

HAL is a multi-disciplinary open access archive for the deposit and dissemination of scientific research documents, whether they are published or not. The documents may come from teaching and research institutions in France or abroad, or from public or private research centers.
L'archive ouverte pluridisciplinaire HAL, est destinée au dépôt et à la diffusion de documents scientifiques de niveau recherche, publiés ou non, émanant des établissements d'enseignement et de recherche français ou étrangers, des laboratoires publics ou privés. 


\title{
Design of near-infrared dyes for nonlinear optics: towards optical limiting applications at telecommunication wavelengths
}

\author{
Quentin Bellier ${ }^{a}$, Pierre-Antoine Bouit, ${ }^{a}$ Kenji Kamada,${ }^{b}$ Patrick Feneyrou, ${ }^{c}$ E. Malmström, ${ }^{d}$ \\ Olivier Maury, ${ }^{a}$ Chantal Andraud ${ }^{a}$ * \\ ${ }^{a}$ Laboratory of Chemistry, Ecole Normale Supérieure de Lyon, UMR CNRS 5182, 69364 \\ LYON Cédex 07 France \\ ${ }^{b}$ AIST Kansai Center, 1-8-37 Middorigaoka, Osaka 563-8577, JAPAN \\ ${ }^{c}$ ThalèsResearch\&Technology, PALAISEAU Cedex, FRANCE \\ ${ }^{d}$ KTH Fibre and Polymer Technology, Royal Institute of Technology, Stockholm, SWEDEN
}

\begin{abstract}
The rapid development of frequency-tunable pulsed lasers up to telecommunication wavelengths (1400-1600 $\mathrm{nm}$ ) led to the design of new materials for nonlinear absorption in this spectral range. In this context, two families of near infra-red (NIR) chromophores, namely heptamethine cyanine and aza-borondipyrromethene (aza-bodipy) dyes were studied. In both cases, they show significant two-photon absorption (TPA) cross-sections in the 1400-1600 nm spectral range and display good optical power limiting (OPL) properties. OPL curves were interpreted on the basis of TPA followed by excited state absorption (ESA) phenomena. Finally these systems have several relevant properties like nonlinear absorption properties, gram scale synthesis and high solubility. In addition, they could be functionalized on several sites which open the way to numerous practical applications in biology, solid-state optical limiting and signal processing.
\end{abstract}

\section{Keywords}

Cyanine, aza-bodipy, two-photon absorption, excited state absorption, nonlinear absorption, optical power limiting, telecommunication wavelength

\section{Introduction}

Systems displaying two-photon absorption (TPA) properties have been widely studied in the visible (400-1000 $\mathrm{nm}$ ), for various applications in the field of material science (3D microfabrication, optical storage, optical power limiting) or in biology (imaging, photodynamic therapy). With the development of frequency-tuneable pulsed laser in the near infrared (NIR) up to telecommunication wavelengths $(1400-1600 \mathrm{~nm})$, there is an increasing need for devices presenting TPA properties in this spectral range. In this context, the challenge is to transpose the TPA model widely studied in the visible to the NIR. Therefore, in recent years, many chromophores have been designed for the optimization of TPA properties in the NIR: dipolar and quadrupolar polyenic chromophores have been reported by Marder's grou ${ }^{[1,2]}$ as well as polymethines cyanine ${ }^{[3]}$ and squarines ${ }^{[4]}$ dyes. In this context, porphyrin monomer complexes ${ }^{[5]}$ and porphyrin macromolecules ${ }^{[6,7]}$ have been described with giant TPA cross-sections. However the multi-photonic absorption based optical power limiting (OPL) properties at telecommunication wavelengths were reported in very few cases with inorganic molecules like $\mathrm{CdSe}^{[8]}$ or $\mathrm{CdTe}^{[9]}$ and octupolar polyenic chromophores. ${ }^{[10,11]}$ In our group we recently described the two-photon absorption based OPL properties of heptamethine cyanine ${ }^{[12]}$ and functionalized aza-borondipyrromethene (azabodipy) ${ }^{[13]}$. In the same time, the OPL properties of borondipyrromethene (bodipy) were studied by Prasad and co-workers. ${ }^{[14]}$ In this article, we want to report the substitution of the cyanine dyes by 2,2bis(methylol)propionic acid based dendrons towards preparation of functional materials for OPL. ${ }^{[15]}$ In a second time, the synthesis aza-borondipyrromethene (aza-bodipy) family has extensively studied. Finally, TPA properties in the NIR spectral range $(1300-1600 \mathrm{~nm})$ were determined using Z-scan technique in the

Optical Materials in Defence Systems Technology VI, edited by James G. Grote, François Kajzar, Roberto Zamboni, Proc. of SPIE Vol. 7487, 74870G · ( 2009 SPIE · CCC code: 0277-786X/09/\$18 · doi: 10.1117/12.831226 
femtosecond (fs) regime. Applications of these chromophores in OPL in the nanosecond (ns) regime will be shown.

\section{Dendron decorated cyanine dyes}

Cyanines dyes are ionic chromophores, in which a charge is delocalized over an odd number of carbon atoms, resulting in an intense NIR absorption. These molecules present (i) an easy two-step synthesis in a gram scale, (ii) a strong TPA and ESA properties at telecommunication wavelengths $(1300-1600 \mathrm{~nm}$ ) and (iii) a good thermal stability.

In addition to these properties, OPL experiments require high solubility in organic solvents without any aggregation phenomenon and quenching of the excited state. In order to avoid this problem, the cyanine dyes have been decorated with dendrons. Then the symmetrical cyanine Cy-1 has been substituted on the mesoposition by a hydroxylbenzyl alcool which was further esterified with anhydride A. Finally, dendrons were attached to the chromophore using "click chemistry" reaction (Scheme 1).

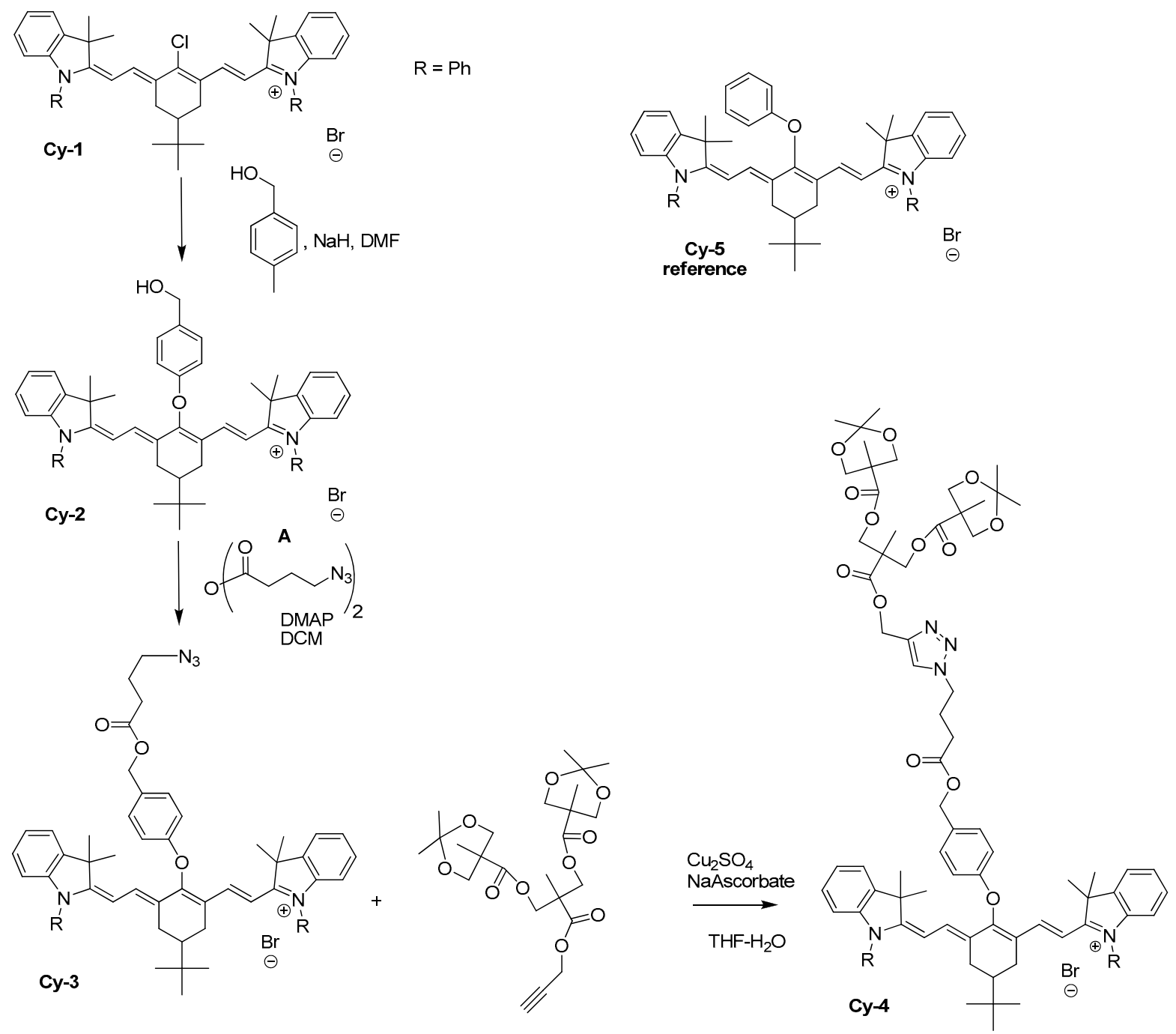

Scheme 1: synthesis of dendron decorated cyanine dyes 
All compounds present the typical linear absorption behavior of cyanine dyes (Table 1): an intense NIR absorption $\left(\lambda_{\max }(\mathbf{C y}-\mathbf{4})=778 \mathrm{~nm}\right.$ and $\varepsilon=210000 \mathrm{~L} \cdot \mathrm{mol}^{-1} \cdot \mathrm{cm}^{-1}$ in DCM $)$ and a shoulder at higher energy. They also show the characteristic emission properties of cyanine with NIR maxima emission $\left(\lambda_{\mathrm{em}}(\mathbf{C y}-\mathbf{4})=803 \mathrm{~nm}\right.$ in DCM). Thus the dendron decorated dye $\mathbf{C y}-\mathbf{4}$ presents similar absorption and emission properties than those of the reference cyanine $\mathbf{C y}-\mathbf{5}$.

\begin{tabular}{|c|c|c|c|c|c|}
\hline compound & $\begin{array}{c}\lambda_{\max } \\
(\mathrm{nm})\end{array}$ & $\begin{array}{c}\varepsilon_{\max } \\
\left(\mathrm{L}_{\mathrm{mol}}{ }^{-1} \cdot \mathrm{cm}^{-1}\right)\end{array}$ & $\begin{array}{c}\lambda_{\mathrm{em}} \\
(\mathrm{nm})\end{array}$ & $\begin{array}{c}\mathrm{T} h^{a} \\
\left(\mathrm{~J} \cdot \mathrm{cm}^{-2}\right)\end{array}$ & $\begin{array}{c}\mathrm{T}_{\min }{ }^{\mathrm{b}} \\
(\%)\end{array}$ \\
\hline $\mathbf{C y - 1}$ & 794 & 350000 & 817 & $0.4 \pm 0.2$ & $70 \pm 5$ \\
\hline $\mathbf{C y - 4}$ & 778 & 210000 & 803 & $0.4 \pm 0.2$ & $70 \pm 5$ \\
\hline $\mathbf{C y - 5}$ & 778 & 190000 & 802 & $0.4 \pm 0.2$ & $70 \pm 5$ \\
\hline
\end{tabular}

${ }^{\mathrm{a}} \mathrm{T} h$ is the optical limiting threshold : this value is graphically determined as the intersection between the linear and the nonlinear part of optical limiting curve.

${ }^{\mathrm{b}} \mathrm{T}_{\min }$ is the transmission reached for the maximal intensity of the laser $\left(2.5 \mathrm{~J}_{\mathrm{cm}} \mathrm{cm}^{-2}\right)$.

Table 1: spectroscopic data of cyanine family

Finally, nonlinear transmission experiments were also carried out (Figure 1) with $1420 \mathrm{~nm}$ as incident wavelength using a ns-optical parametic oscillator pumped by a frequency tripled Nd:YAG laser source.The dendronnized chromophore $\mathbf{C y}-\mathbf{4}$, its precursor $\mathbf{C y}-\mathbf{1}$ and the reference $\mathbf{C y}-\mathbf{5}$ show the characteristic behavior of optical limiters at telecommunication wavelengths with very similar characteristics (optical limiting threshold $\mathrm{T} h=0.4 \mathrm{~J} . \mathrm{cm}^{-2}$, minimal transmission $\mathrm{T}_{\min }=70 \%$ at $\left.1420 \mathrm{~nm}\right) .{ }^{[12,15]}$

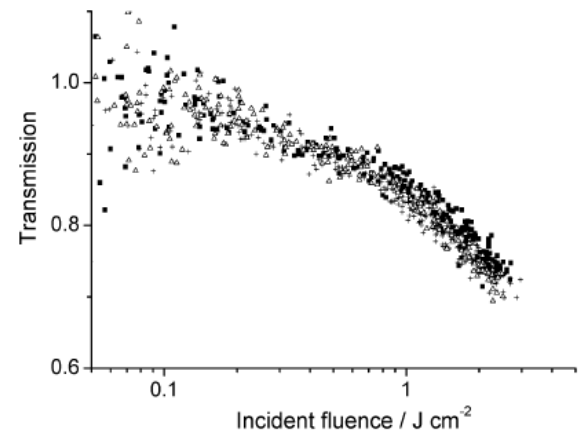

Figure 1: nonlinear transmittance curves at $1420 \mathrm{~nm}$ in DCM for Cy-1 $(\Delta), \mathrm{Cy}-4(\quad)$ and Cy-5 (reference) $\mathbf{C})(\mathrm{c}=0.1$ mol.L ${ }^{1}$ )

As the linear and nonlinear optical properties between the final compound $\mathbf{C y}-\mathbf{4}$ with dendrons and its reference Cy-5 without dendrons are nearly identical, we can conclude that the presence of dendrons has no effect on the spectroscopic properties. The dendron synthesis approach seems also to be a good way to investigate the solid state properties of these chromophores. 


\section{Functionalized aza-bodipy}

Bodipy are widely studied for their fluorescent properties but rarely for their NLO properties. Our study is focused on the NIR absorbing aza-bodipy (aza-borondipyrromethene). These chromophores have an extended aromatic conjugated skeleton, improved by a rigidification with a Lewis acid group like $\mathrm{BF}_{2}$ and the presence of the meso nitrogen atom contributed to shift the absorption spectra in the NIR. ${ }^{[16]}$ In order to increase the NLO properties and to further shift the absorption into the NIR, electron donating moieties have been introduced on the periphery of the dye. Therefore, the aza-bodipy dyes are a versatile class of chromophore since functionalization should be performed at the $\mathrm{R}_{1}, \mathrm{R}_{2}, \mathrm{R}_{3}$ and $\mathrm{R}_{4}$ positions (Figure 2).
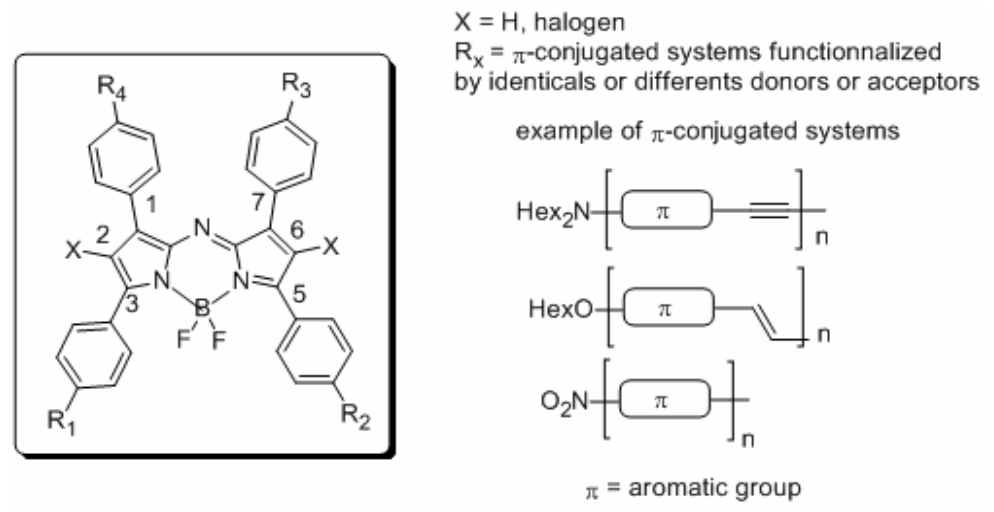

Figure 2: aza-bodipy dyes

To that end, three different synthetic routes have been explored. For all of them, the synthesis began with the formation of chalcone derivatives by condensation between bromoacetophenone and benzaldehyde in basic medium. Then the nitration of the chalcone was carried out by nitromethane and diethylamine in methanol at reflux overnight. The key-step of functionalization, ie Sonogashira cross-coupling reaction differentiates the three ways (Sheme2):

route 1: functionalization on the aza-bodipy level.

route 2: functionalization on the dipyrromethene level.

route 3: functionalization and cyclisation on the nitro-chalcone level.

The cyclisation in dipyrromethene was generally performed with sublimated ammonium acetate in anhydrous butanol during two days, followed by classical complexation with boron trifluoride etherate in DCM in the presence of Hünig's base. Unfortunately, it was impossible to functionalize the $\mathbf{B}^{1}$ precursor (route 1). The second route gave correct yields but was restricted to one side of functionalization (up or down). 


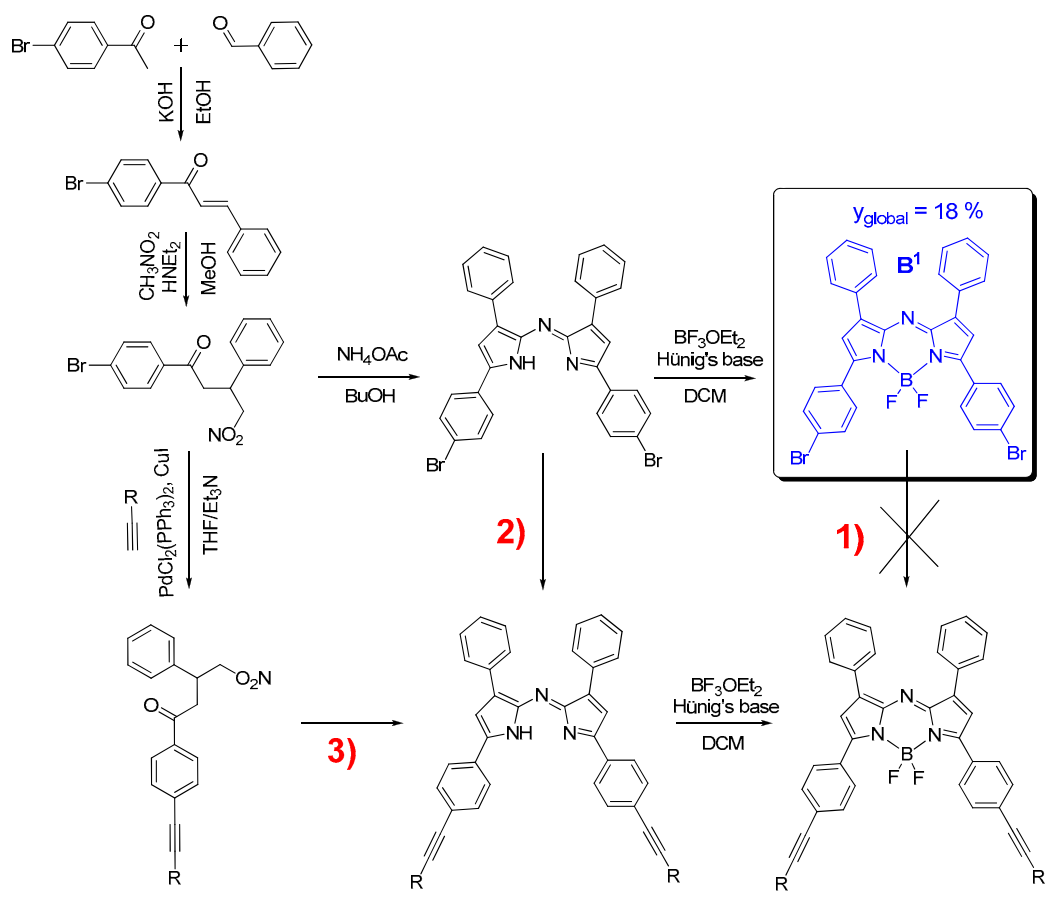

Scheme 2: three different routes for aza-bodipy dyes

Finally the third route was a general method of functionalization for all positions, donors and acceptors but presented low yields and purification difficulties.

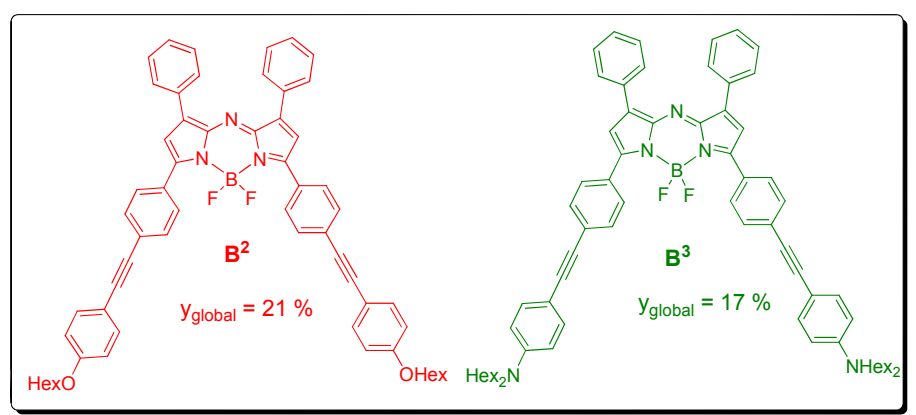

Figure 3: donors substituted aza-bodipy dyes $\mathrm{B}^{2}$ and $\mathrm{B}^{3}$

Nevertheless the synthesis of compounds $\mathbf{B}^{2}$ and $\mathbf{B}^{3}$ (Figure 3 ) have been achieved by the second route and their linear and nonlinear properties were studied in dichloromethane. These molecules show a very intense NIR linear absorption $\left(\lambda_{\max }\left(\mathbf{B}^{3}\right)=745 \mathrm{~nm}\right.$ and $\varepsilon=57000 \mathrm{~L} \cdot \mathrm{mol}^{-1} \cdot \mathrm{cm}^{-1}$ in DCM) with transitions whose red shift increases with the strength of the donor group $\left(\Delta \lambda=37\right.$ and $87 \mathrm{~nm}$ between $\mathbf{B}^{\mathbf{1}}-\mathbf{B}^{\mathbf{2}}$ and $\mathbf{B}^{\mathbf{1}}-\mathbf{B}^{3}$ respectively). Zscan measurements were performed in the $1200-1600 \mathrm{~nm}$ spectral range using a fs-optical parametic amplifier pumped by a Ti/sapphire source. At such short pulse durations (130 fs), only the TPA phenomenon takes place. At these telecommunication wavelengths, the compound $\mathbf{B}^{\mathbf{1}}$ does not present any TPA response, as opposed to the donor substituted compounds $\mathbf{B}^{2}$ and $\mathbf{B}^{3}$ (Table 2 and Figure 4). While molecule $\mathbf{B}^{1}$ shows a small nonlinear 
optical activity, chromophore $\mathbf{B}^{3}$ presents very broad TPA properties between 1200 and $1450 \mathrm{~nm}\left(\sigma_{\mathrm{TPA}}=1070\right.$ $\mathrm{GM}$ at $1220 \mathrm{~nm})$.

\begin{tabular}{|c|c|c|c|c|c|c|}
\hline compound & $\begin{array}{c}\lambda_{\max } \\
(\mathrm{nm})\end{array}$ & $\begin{array}{c}\varepsilon \\
\left(\mathrm{L} \cdot \mathrm{mol}^{-1} \cdot \mathrm{cm}^{-1}\right)\end{array}$ & $\begin{array}{c}\lambda_{\mathrm{em}} \\
(\mathrm{nm})\end{array}$ & $\begin{array}{c}\lambda^{\mathrm{TPA} \max } \\
(\mathrm{nm})\end{array}$ & $\begin{array}{c}\sigma_{\mathrm{TPA} \max } \\
(\mathrm{GM})\end{array}$ & $\begin{array}{c}\alpha_{3}{ }^{\mathrm{a}} \\
\left(\mathrm{cm}^{3} \mathrm{GW}^{-2}\right)\end{array}$ \\
\hline $\mathbf{B}^{1}$ & 658 & 83000 & 686 & - & $<20$ & - \\
\hline $\mathbf{B}^{2}$ & 695 & 80000 & 735 & 1440 & $80 \pm 10$ & - \\
\hline $\mathbf{B}^{3}$ & 745 & 57000 & 790 & 1220 & $1070 \pm 100$ & $620(1350)$ \\
\hline
\end{tabular}

${ }^{\mathrm{a}}$ Deduced from ns-nonlinear transmittance experiments for a concentration of 106 g.L ${ }^{-1}$.

Table 2: spectroscopic data of aza-bodipy dyes $\mathbf{B}^{\mathbf{1}}-\mathbf{B}^{\mathbf{3}}$
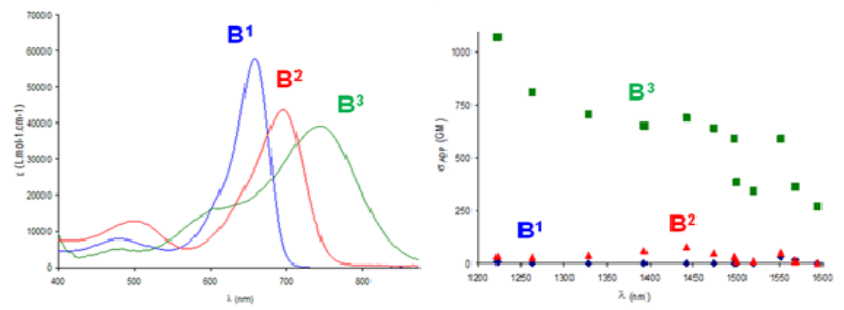

Figure 4: linear absorption and TPA (fs Z-scan) spectra of aza-bodipy dyes in DCM

Furthermore, thanks to the high solubility of compound $\mathbf{B}^{3}\left(0.1\right.$ mol. $\mathrm{L}^{-1}$ in DCM), nonlinear transmission experiments were also carried out with $1500 \mathrm{~nm}$ as incident wavelength using a ns-optical parametric oscillator pumped by a frequency tripled Nd:YAG laser source. This molecule $\mathbf{B}^{\mathbf{3}}$ has also a typical behavior of optical limiter at telecommunication wavelength (optical limiting threshold $\mathrm{T} h=0.7 \mathrm{~J} . \mathrm{cm}^{-2}$, minimal transmission $\mathrm{T}_{\min }=60 \%$ at $1350 \mathrm{~nm}$ ). Due to the longer pulse duration $(7 \mathrm{~ns})$, the simulation of the experimental curves based only on a TPA process failed. However when a third order effect, such as an excited state absorption (ESA), was added, the simulation carried out successfully. Consequently, the nonlinear optical phenomenon has been interpreted on the basis of the absorption of $2+1$ photons: the TPA process is followed by ESA phenomenon (Figure 5).
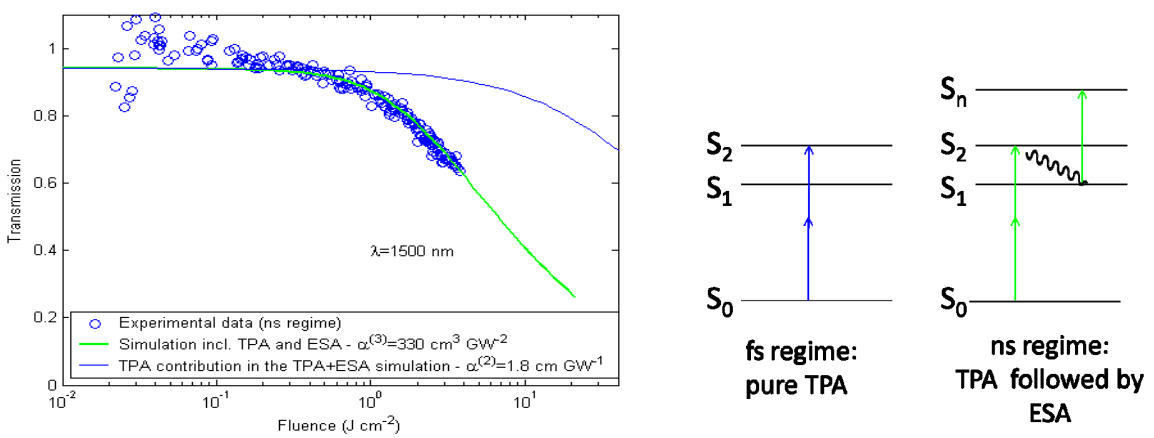

Figure 5: nonlinear transmittance at $1500 \mathrm{~nm}$ and interpretation 
The authors thank the Direction Générale de l'Armement for grants to P-A. B. and Q. B.

${ }^{[1]}$ Beverina, L., Fu, J., Leclercq, A., Zojer, E., Pacher, P., Barlow, S., Van Stryland, E.,W., Hagan, D.J., Brédas, J.,L., S.,R., Marder, S.,R., "Two-Photon Absorption at Telecommunications wavelengths in a Dipolar Chromophore with a Pyrrole Auxiliary Donor and Thiazole Auxiliary Acceptor" J. Am. Chem. Soc. 127, 72827283 (2005)

${ }^{[2]}$ Zheng, Q., Leclercq, A., Fu, J., Beverina, L., Padilha, L.,A., Zojer, E., Schmidt, K., Barlow, S., Luo, J., Jiang, S.-H., Jen, A. K.-Y., Yi, Y., Shuai, Z., Van Stryland, E.,W., Hagan, D.J., Brédas, J.,L., S.,R., Marder, S.,R., "Two-Photon Absorption in Quadrupolar Bis(acceptor)-Terminated Chromophores with Electron-Rich Bis(heterocycle)vinylene Bridges" Chem. Mater., 19, 432-442 (2007)

${ }^{[3]}$ Hales, J.,H., Zheng, S., Barlow, S., Marder, S.,R., Perry, J.,W., "Bisdioxaborine polymethines with large third-order nonlinearities for all-optical signal processing” J. Am. Chem. Soc. 128, 11362-11363 (2006)

${ }^{[4]}$ Chung, S.,J., Zheng, S, Odani, S.,T., Beverina, L., Fu, J., Padilha, L.,A., Biesso, A., Hales, J.,M., Zhan, X., Schmidt, K., Ye, A., Zojer, E., Barlow, S., Hagan, D.J Van Stryland, E.,W., Yi, Y., Shuai, Z., Pagani, G.,A,. Brédas, J.,L., Perry, J.,W., Marder, S.,R., "Extended squaraine with large two-photon absorption cross-sections" J. Am. Chem. Soc., 128, 14445-14446 (2006)

${ }^{[5]}$ Kurotobi, K., Kim, K.,S., Noh, S.,B., Kim, D., Osuka, A., "A Quadruply Azulene-Fused Porphyrin with Intense Near-IR Absorption and a Large Two-Photon Absorption Cross Section" Angew. Chem. Int. Ed., 45, 3944-3947 (2006)

${ }^{[6]}$ Mori, S., Kim, K.,S., Yoon, Z.,S., Noh, S.,B., Kim, D., Osuka, A., "Peripheral Fabrications of a Bis-Gold(III) Complex of [26]Hexaphyrin(1.1.1.1.1.1) and Aromatic versus Antiaromatic Effect on Two-Photon Absorption Cross Section" J. Am. Chem. Soc., 129, 11344-11345 (2007)

${ }^{[7]}$ Drobizhev, M., Stepanenko, Y., Rebane, Wilson, A.,J., Sreen, T.,E.,O., Anderson, H.,L., "Strong cooperative enhancement of two-photon absorption in double-strand conjugated porphyrin ladder arrays" J. Am. Chem. Soc., $128,12432-12433(2006)$

${ }^{[8]}$ He, G.,S., Yong, K.-T., Zheng, Q., Sahoo, Y., Baev, A. Ryasnyanskiy, A.,I., Prasad, P.,N., "Multi-photon excitation properties of CdSe quantum dots solutions and optical limiting behavior in infrared range" Opt. Express, 15, 12818-12833 (2007)

${ }^{[9]}$ He, G.,S., Zheng, Q., Yong, K.-T., Ryasnyanskiy, A.,I., Prasad, P.,N.,, Urbas, A., "Two-photon absorption based optical limiting and stabilization by using a CdTe quantum dot solution excited at optical communication wavelength of $\sim 1300 \mathrm{~nm}$ " Appl. Phys. Lett., 90, 181108-3 (2007)

${ }^{[10]}$ Zheng, Q., He, G.,S., Baev, A., Prasad, P.,N., "Experimental and Quantum Chemical Studies of Cooperative Enhancement of Three-Photon Absorption, Optical Limiting, and Stabilization Behaviors in Multibranched and Dendritic Structures" J. Phys. Chem. B 110, 14604-14610 (2006)

${ }^{[11]}$ Lin, T.-C., ., Zheng, Q., Chen, C.-Y., He, G.,S., Huang, W.-J., Ryasnyanskiy, A.,I., Prasad, P.,N., "Novel fluorophore based on a multisubstituted olefin skeleton with enhanced three-photon absorption in the femtosecond regime" Chem. Comm., 3, 389-391 (2008)

${ }^{[12]}$ Bouit, P.-A., Wetzel, G., Berginc, G., Loiseaux, B., Toupet, L., Feneyrou, P., Bretonnière, Y., Kamada, K., Maury, O., Andraud, C., "Near IR Nonlinear Absorbing Chromophores with Optical Limiting Properties at Telecommunication Wavelengths" Chem. Mater, 19, 5325-5335 (2007)

${ }^{[13]}$ Zheng, Q, He, G.,S., Prasad, P.,N., "A novel near IR two-photon absorbing chromophore: Optical limiting and stabilization performances at an optical communication wavelength" Chem. Phys. Lett., 475, 250-255 (2009)

${ }^{[14]}$ Bouit, P.-A., Kamada, K., Feneyrou, P., Berginc, G., Toupet, L., Maury, O., Andraud, C., "Two-Photon Absorption-Related Properties of functionalized BODIPY Dyes in the Infrared Range up to Telecommunication Wavelengths" Adv. Mater., 21, 1151-1154 (2009)

${ }^{[15]}$ Bouit, P.-A., Westlund, R., Feneyrou, P., Maury, O., Malkoch, M., Malmström, E., Andraud, C., "Dendron decorated cyanine dyes for optical limiting applications at telecommunication wavelengths" New J. Chem., 33, 964-968 (2009)

${ }^{[16]}$ Zhao, W., Carreira, E.,M, "Conformationally Restricted aza-BODIPY: Highly Fluorescent, Stable NearInfrared Absorbing Dyes" Chem. Eur. J., 12, 7254-7258 (2006) 